\title{
Patients lost to follow-up in acromegaly: results of the ACROSPECT study
}

\author{
B Delemer, Ph Chanson ${ }^{1}$, L Foubert ${ }^{2}$, F Borson-Chazot ${ }^{3}$, o Chabre ${ }^{4}$, A Tabarin ${ }^{5}$, \\ G Weryha $^{6}$, C Cortet-Rudelli' , I Raingeard ${ }^{8}$, Y Reznik ${ }^{9}$, C Reines $^{10}$, \\ S Bisot-Locard ${ }^{10}$ and F Castinetti ${ }^{11}$
}

Service d'Endocrinologie-Diabète-Nutrition, CHU de Reims-Hôpital Robert-Debré, 51092 Reims, France, 'Service d'Endocrinologie et des Maladies de la Reproduction, Centre de Référence des Maladies Endocriniennes Rares de la Croissance, Inserm UMR S693, Hôpitaux Universitaires Paris-Sud, AP-HP, 94275 Le Kremlin Bicêtre, France, ${ }^{2}$ Services de Neurochirurgie et de Médecine Interne-Diabétologie, Hôpital Foch, 92151 Suresnes, France, ${ }^{3}$ Fédération d'Endocrinologie, Hospices Civils de Lyon, 69677 Bron, France, ${ }^{4}$ Service d'Endocrinologie-Diabétologie-Nutrition, CHU de Grenoble-Hôpital Albert Michallon, 38043 Grenoble, France, 5 Service d'Endocrinologie-Diabétologie et Maladies Métaboliques, CHU de Bordeaux-Hôpital du Haut Lévêque, 33604 Pessac, France, ${ }^{6}$ Service d'Endocrinologie, CHU de Nancy-Hôpital de Brabois, 54511 Vandoeuvre-les-Nancy, France, ${ }^{7}$ Clinique Linquette, CHRU de Lille, 59037 Lille, France, ${ }^{8}$ Service des Maladies Endocriniennes, CHU de Montpellier-Hôpital Lapeyronie, 34295 Montpellier, France, ${ }^{9}$ Service d'Endocrinologie, CHU de Caen - Côte de Nacre, 14033 Caen, France, ${ }^{10}$ Novartis Pharma SAS, 92500 Rueil-Malmaison, France and ${ }^{11}$ Service d'Endocrinologie, Diabète et Maladies Métaboliques, Centre de Référence des Maladies Rares d'origine Hypophysaire, Aix-Marseille Université-Hôpital de la Timone, AP-HM, 13385 Marseille, France

Correspondence should be addressed to B Delemer

Email

bdelemer@chu-reims.fr

\begin{abstract}
Objective: The complex management of acromegaly has transformed this disease into a chronic condition, with the risk of patients being lost to follow-up. The objective of this study was to estimate the proportion of acromegalic patients lost to follow-up in France and to determine the impact that abandoning follow-up has on the disease and its management.

Design: ACROSPECT was a French national, multicentre, cross-sectional, observational study.

Methods: Acromegalic patients were considered lost to follow-up if no new information had been entered in their hospital records during the previous 2 years. They were traced where possible, and data were collected by means of a recall visit or questionnaire.

Results: In the study population, $21 \%$ of the 2392 acromegalic patients initially followed in 25 tertiary endocrinology centres were lost to follow-up. At their last follow-up visit, 30\% were uncontrolled, 33\% were receiving medical therapy and $53 \%$ had residual tumour. Of the 362 traced, 62 had died and $77 \%$ were receiving follow-up elsewhere; the leading reason for abandoning follow-up was that they had not been informed that it was necessary. Our analysis of the questionnaires suggests that they were not receiving optimal follow-up.

Conclusions: This study underlines the need to better inform acromegalic patients of the need for long-term follow-up, the absence of which could be detrimental to patients' health, and to develop shared care for what must now be regarded as a chronic disease.
\end{abstract}

\section{Introduction}

Acromegaly is a rare disease, usually due to a somatotroph pituitary adenoma (1). If undiagnosed or inadequately treated, acromegaly reduces quality of life and increases morbidity and mortality $(2,3)$. Pituitary surgery is the first-line treatment, producing remission in $40-50 \%$ of cases. When surgery fails or is contraindicated, adjunctive therapy is needed, mainly somatostatin analogues and, to a lesser extent, dopamine agonists, growth hormone $(\mathrm{GH})$ (c) 2014 European Society of Endocrinology Printed in Great Britain
Published by Bioscientifica Ltd. 
receptor antagonists or radiotherapy, as recommended in several recent consensus guidelines $(1,4,5,6)$. These treatments usually control the disease effectively, and normalising levels of GH and insulin-like growth factor 1 (IGF1) should reduce the excess morbidity and mortality associated with acromegaly $(4,7,8)$. However, recent studies have shown that there was a relatively low percent of patients with acromegaly who might be cured after withdrawal of somatostatin analogues (up to $20 \%)(9,10)$. This means that these treatments should be monitored regularly on a lifelong basis, and as a consequence, that acromegaly has become a chronic disease requiring regular follow-up.

In a healthcare system that tends to focus on acute disease, it is difficult to organise long-term follow-up for any chronic disease. In addition, patients with chronic disease can lose motivation in the face of lifelong followup that requires active participation, especially when their disease is adequately controlled with a constant dose of treatment. Support must be provided to help them adhere to their drug therapy. As a result, loss to follow-up is frequent in patients with chronic disease, although precise numbers tend to be difficult to obtain. A recent study based on a small number of acromegalic patients $(n=239)$ has reported that $17.6 \%$ of the patients were lost to follow-up (11).

The aim of the ACROSPECT study was to determine the proportion of a large French population of acromegalic patients that was lost to follow-up. The study was designed to cover a large area of France. Secondary aims were to determine why patients were lost to follow-up and to evaluate the impact of abandoning follow-up on acromegaly and its clinical management, by means of a questionnaire or recall visit.

\section{Subjects and methods}

ACROSPECT is an observational, cross-sectional, multicentre study carried out in 25 French tertiary endocrinology centres between June 2009 and July 2010. We analysed data on all the patients followed for acromegaly between January 1997 and December 2006. Patients were identified from a national medical information system (Programme de Médicalisation des Systèmes d'Information (PMSI)), each hospital medical records and the French acromegaly registry.

Patients were considered lost to follow-up if they had not attended a follow-up visit in the department, or if the department had received no new clinical data from an endocrinologist, for at least 2 years. The list of patients was double-checked at each tertiary centre to make sure that the patients lost to follow-up as far as the study centre was concerned were not being followed in another centre: those being followed in another tertiary centre were not included in the study.

Each of these patients was contacted by postal mail, a reminder was sent 15 days later, followed by a phone call 30 days after the initial letter. The last doctor known to have provided care to the patient was contacted in the same way. Data could be updated on all traced patients by means of a recall visit or by questionnaire or telephone (Fig. 1). When neither the patient nor doctor could be contacted, the patient was considered permanently lost to follow-up. The study protocol was approved by the French health authorities (CCTIRS-CNIL).

\section{Data collected}

We recorded the number of patients followed in each department and the number lost to follow-up. A retrospective analysis of the data on each patient lost to followup was carried out to collect the following:

i) at diagnosis: demographic data, date of diagnosis and adenoma characteristics and

ii) at their last follow-up visit: adenoma characteristics, treatment modalities, last IGF1 level and disease status.

At their last follow-up visit, patients were considered:

i) controlled without treatment if their age-adjusted IGF1 level was normal without ongoing medical treatment,

ii) controlled with treatment if their age-adjusted IGF1 level was normal with antisecretory treatment and

iii) uncontrolled if their IGF1 level was elevated.

Patients we managed to trace were asked to state their reasons for abandoning follow-up in the tertiary endocrinology centre, the type of medical follow-up they had received since their last visit at the centre, and, when available, last IGF1 value, magnetic resonance imaging (MRI) result and current treatment for acromegaly. For patients lost to follow-up who returned for the recall visit, the data collected included the endocrinologist's evaluation of their disease status.

\section{Statistical analysis}

Descriptive statistics are provided to summarise the characteristics of the patients recruited. Quantitative 


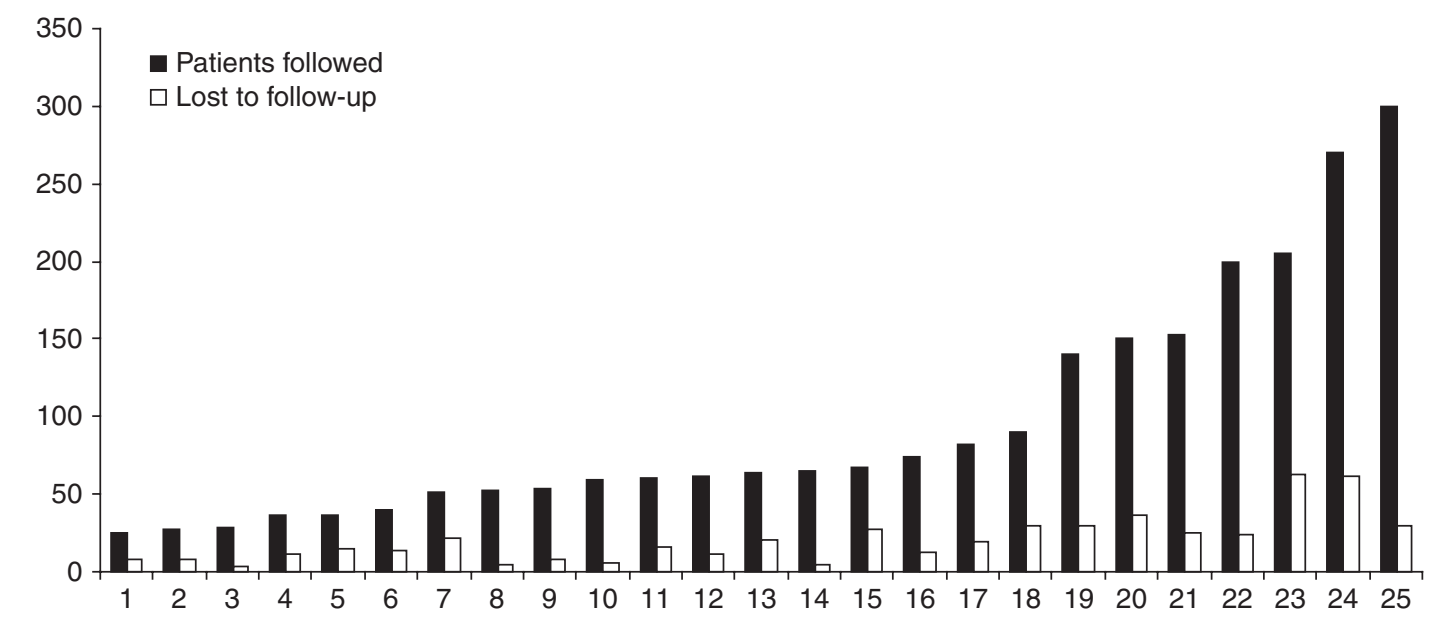

\begin{tabular}{|c|r|r|r|r|r|r|r|r|r|r|r|r|r|r|r|r|r|r|r|r|r|r|r|r|r|}
\hline Centre & 1 & 2 & 3 & 4 & 5 & 6 & 7 & 8 & 9 & 10 & 11 & 12 & 13 & 14 & 15 & 16 & 17 & 18 & 19 & 20 & 21 & 22 & 23 & 24 & 25 \\
\hline Patients followed & 25 & 27 & 28 & 37 & 37 & 40 & 51 & 53 & 54 & 59 & 60 & 61 & 64 & 65 & 67 & 74 & 82 & 90 & 140 & 150 & 153 & 200 & 205 & 270 & 300 \\
\hline Lost to follow-up & 8 & 8 & 3 & 11 & 15 & 14 & 22 & 5 & 8 & 6 & 16 & 11 & 20 & 5 & 27 & 13 & 19 & 30 & 30 & 37 & 25 & 24 & 63 & 62 & 30 \\
\hline Percentage of lost to follow-up & 32.0 & 29.6 & 10.7 & 29.7 & 40.5 & 35.0 & 43.1 & 9.4 & 14.8 & 10.2 & 26.7 & 18.0 & 31.3 & 7.7 & 40.3 & 17.6 & 23.2 & 33.3 & 21.4 & 24.7 & 16.3 & 12.0 & 30.7 & 23.0 & 10.0 \\
\hline
\end{tabular}

\section{Figure 1}

Number of patients followed and lost to follow-up in each centre.

variables are expressed as mean, s.D., median and range, and qualitative variables as absolute frequency and the percentage in each category.

\section{Results}

Twenty-five tertiary endocrinology departments took part in this study. We analysed a total of 2392 patients who had been followed in these centres in the last 10 years (mean number of patients per centre, 94; median, 62 and range, 25-300; Fig. 1).

A total of 512 patients were considered lost to followup, i.e. $21 \%$ of the patients, with a wide inter-centre variability (range, $8-43 \%$ and median, 24\%).

We managed to contact 362 patients or their doctor and the remaining 150 were considered permanently lost to follow-up (i.e. $6 \%$ of the total population and $29 \%$ of the population of patients lost to follow-up; Fig. 2): 62 of these 362 patients were deceased.

\section{Retrospective data on patients lost to follow-up}

The mean age of these patients at their last follow-up visit was 54 years (median, 54 years and range, 11-95 years). The time since diagnosis of acromegaly ranged from $<1$ to 53 years and was $>5$ years for more than half of the population (57\%). Patients had been followed for a mean of 8.9 years (median, 6.1 years and range, $0-53.8$ years). In $22 \%$ of cases, the last follow-up data available in the Department of Endocrinology had been obtained within the past 4 years, and in $78 \%$ of cases the data were more than 4 years old. Precise characteristics of the whole population are shown in Table 1.

In terms of medical therapy, 167 patients (33\%) were taking at least one antisecretory drug, including a somatostatin analogue in $81 \%$ of cases $(n=136)$, a dopamine agonist in $23 \%$ of cases $(n=39)$ and a $\mathrm{GH}$ receptor antagonist in $8 \%$ of cases $(n=13)$. The majority of patients (490/512) had their IGF1 level measured at their last visit: IGF1 was elevated in $31 \%$ of patients. Their acromegaly was considered controlled without treatment in 54\% of cases, controlled with medical treatment in 16\% of cases and uncontrolled for 30\% of patients. A pituitary MRI was available for $75 \%$ patients, showing a pituitary remnant in $53 \%$ of cases (Table 1 ).

\section{Data updates on patients we traced}

We managed to contact 300 patients who were lost to follow-up, 87 of whom agreed to attend a recall visit. The others agreed to complete a written questionnaire.

The reason for abandoning follow-up was identified for 206 patients (Table 2). The reason most frequently given was that the patient had not been informed of the 


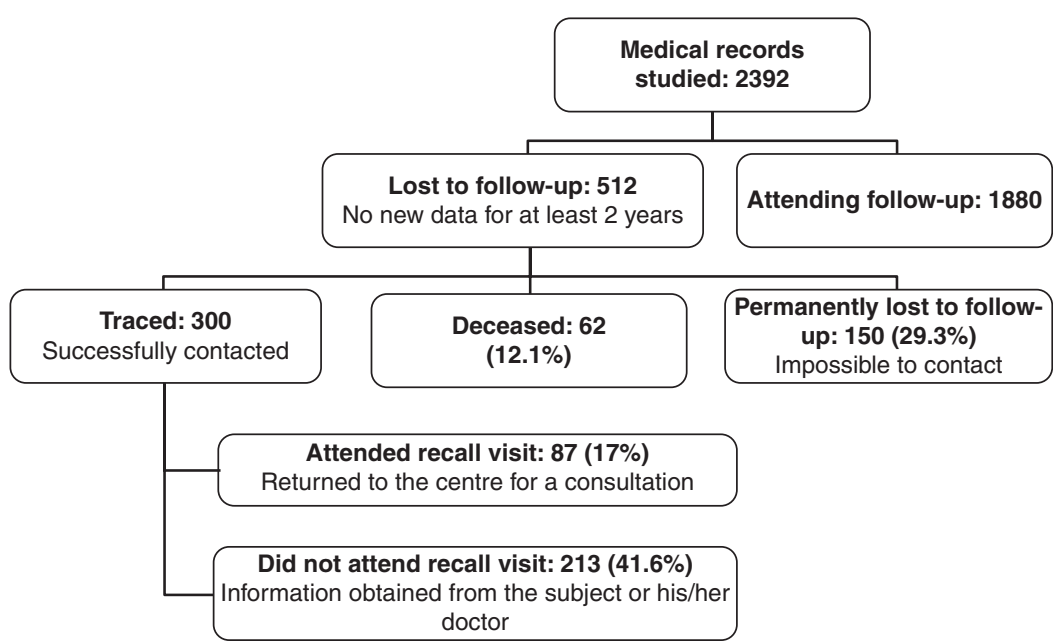

\section{Figure 2}

Flow chart showing the total number of patients lost to follow-up and the results of active tracing. Percentages are expressed in relation to the total number lost to follow-up, i.e. 512.

need to continue follow-up; patients also stopped followup because they had moved away or had difficulties getting to the Department of Endocrinology. Interestingly, $77 \%$ of patients were still being followed by a physician, usually a general practitioner (Table 3). The remaining $23 \%$ of patients were no longer receiving follow-up. Only a small percentage of patients strictly refused the follow-up (7\%). Of note, $7 \%$ of the other

Table 1 Data for the patients lost to follow-up obtained at their last standard clinic visit.

\begin{tabular}{l}
\hline Sex ratio (F:M) \\
Mean age (years) \\
Adenoma \\
Microadenoma \\
Macroadenoma \\
Surgery \\
Radiotherapy \\
Medical treatment \\
Last visit \\
$2-4$ years \\
$4-10$ years \\
$>10$ years \\
Mean follow-up length (years) \\
GH level ( $n=332$ ) \\
$<2.5$ ng/ml \\
$\geq 2.5$ ng/ml \\
IGF1 level ( $n=490$ ) \\
Normal \\
Increased \\
MRI last visit \\
No remnant \\
Remnant
\end{tabular}

patients considered the follow-up too demanding and 6\% considered it unnecessary (Table 3).

\section{Disease status since abandoning follow-up}

The data obtained from patients or their doctor were incomplete (Table 4). Of the 213 patients who answered by questionnaire, only 61 were able to provide their last IGF1 result and 37 their last MRI result. Among the patients who attended the recall visit, 20\% had elevated IGF1 levels, whereas only $12 \%$ of the same group of patients had elevated IGF1 levels at their last available follow-up visit in the department.

Seven patients had been treated with surgery or radiotherapy since abandoning follow-up at the tertiary centre. The number of patients taking medical therapy was markedly lower than at the last follow-up visit. Up to $15 \%$ of patients who attended the recall visit were taking medical therapy, compared with $22 \%$ at the last follow-up visit. The proportion of uncontrolled patients had increased from $17 \%$ at the last follow-up visit to $21 \%$ at the recall visit, mainly due to a decrease in the number of patients controlled with medical treatment (10 vs $16 \%$ at last follow-up visit). In contrast, the proportion of patients controlled without medical treatment had remained stable.

Similar results were observed in the 213 patients who responded by questionnaire or telephone: $15 \%$ were taking medical treatment compared with 30\% at the last follow-up visit in the department. It is noteworthy that 
Table 2 Reasons for loss to follow-up.

\begin{tabular}{|c|c|c|c|}
\hline & Found & $\begin{array}{l}\text { Information } \\
\text { at a new } \\
\text { visit }\end{array}$ & $\begin{array}{c}\text { Information by } \\
\text { questionnaire/ } \\
\text { phone }\end{array}$ \\
\hline $\begin{array}{l}n \\
\text { Reasons for loss to } \\
\text { follow-up }\end{array}$ & 300 & 87 & 213 \\
\hline $\begin{array}{l}\text { Followed by another } \\
\text { practitioner (GP, } \\
\text { endocrinologist or } \\
\text { other) }\end{array}$ & 143 & 35 & 108 \\
\hline Lack of information & 44 & 37 & 7 \\
\hline Moved & 22 & 1 & 21 \\
\hline $\begin{array}{l}\text { Difficulties to come to } \\
\text { the visit }\end{array}$ & 18 & 1 & 17 \\
\hline Opposed to follow-up & 40 & 17 & 23 \\
\hline Others & 11 & 3 & 8 \\
\hline Missing data & 94 & 7 & 87 \\
\hline
\end{tabular}

99\% of the patients traced who attended the recall visit agreed to resume regular follow-up.

\section{Discussion}

Despite the advances made in pituitary surgery, acromegaly has become a chronic disease that requires multimodal management and regular follow-up of its various complications $(1,4,6)$. Current clinical management is effective, and in most cases enables long-term control of the disease. The quality of the follow-up is therefore a major issue. The French consensus on the management of acromegaly, developed by the French Endocrinology Society, recommends an annual consultation with a specialist and regular defined tests $(12,13)$. This is especially important since drug therapy for acromegaly is usually inconvenient and expensive (14).

The issue of loss to follow-up in chronic diseases is often mentioned but rarely studied. Its prevalence is hard to assess (difficulties of definition and limitations of information systems), as is its impact on patients' health. Recent studies have estimated the percentage of subjects lost to follow-up in a variety of chronic diseases: $8.5-16.5 \%$ in HIV infection (15), 6\% in tuberculosis in France (16) and $11 \%$ in stage I melanoma with follow-up in day hospital, despite systematic recall (17). Very few data are available in pituitary diseases, and even fewer in acromegaly (11).

The definition of loss to follow-up adopted in our study, i.e. no information added to the medical records for 2 years, is consistent with usual clinical practice and French and International guidelines, since 2 years is the maximum recommended interval between follow-up visits, even for patients in remission. The estimated prevalence of acromegaly is 40-124 cases/million population, which corresponds to between 2400 and 7740 patients in France. Our study population of 2392 patients is therefore large enough to be considered as representative of the French population $(18,19)$.

The average prevalence of loss to follow-up of $21 \%$ in our study is similar to the results of a Brazilian study (42 of 239 patients) (11) and an Italian study (11 of 159 patients) (20). The lower prevalence reported in some national registries is probably related to the fact that the studies were not designed to answer this question $(21,22)$. The prevalence varied considerably between our centres, ranging from 8 to $43 \%$ (Fig. 1), and was unrelated to the number of patients still being monitored there. Analysis of the differences in the organisation of follow-up between these centres may prove useful in reducing the numbers lost to follow-up in the future.

Considerable resources were mobilised for the ACROSPECT study to actively trace patients lost to follow-up: 362 of 512 patients lost to follow-up were indeed traced and information was updated in all these individuals. In contrast, despite these efforts, 150 patients remained untraceable, i.e. $6 \%$ of the population of acromegalic patients studied. For these patients, we considered that having the rate of death would not be enough information as we would not have found the reason for death, and if death was due to acromegaly lack of follow-up may have been detrimental. We cannot exclude that the responding patients were only the ones who had enough knowledge of their disease to maintain a minimal surveillance (despite the fact that they were lost to follow-up), and that outcome would have been worse if we had managed to contact the whole cohort. Another missing characteristic could be that we did not have detailed data trying to compare the appropriate follow-up in patients followed by an endocrinologist or another practitioner, which would have emphasised the need for specialised monitoring.

Table 3 Medical contact during the loss to follow-up period. Data given as $n$, with percentage of patients after excluding missing data given in parentheses. Note that some patients were followed by more than one doctor type.

\begin{tabular}{|c|c|c|c|}
\hline & Found & $\begin{array}{l}\text { Information } \\
\text { at a new visit }\end{array}$ & $\begin{array}{c}\text { Information by } \\
\text { questionnaire/ } \\
\text { phone }\end{array}$ \\
\hline$n$ & 300 & 87 & 213 \\
\hline No & $50(23.4)$ & $36(42.9)$ & $14(10.8)$ \\
\hline GP & $96(44.9)$ & $42(50)$ & $54(41.5)$ \\
\hline Endocrinologist & $72(33.6)$ & $7(8.3)$ & $65(50)$ \\
\hline Other practitioner & $6(2.8)$ & $3(3.6)$ & $3(2.3)$ \\
\hline Missing data & 86 & 3 & 83 \\
\hline
\end{tabular}


Table 4 Biological and imaging evaluation at new visit/ contact. Data given as $n$, with percentage of patients after excluding missing data given in parentheses.

\begin{tabular}{|c|c|c|c|}
\hline & Found & $\begin{array}{c}\text { Information at } \\
\text { a new visit }\end{array}$ & $\begin{array}{c}\text { Information by } \\
\text { questionnaire/ } \\
\text { phone }\end{array}$ \\
\hline$n$ & 300 & 87 & 213 \\
\hline \multicolumn{4}{|l|}{ IGF1 level } \\
\hline Normal & $108(78.8)$ & $61(80.3)$ & $47(77)$ \\
\hline Increased & $29(21.2)$ & $15(19.7)$ & $14(23)$ \\
\hline Missing data & 163 & 11 & 152 \\
\hline \multicolumn{4}{|l|}{ MRI } \\
\hline No remnant & $41(60.3)$ & 24 (77.4) & $17(45.9)$ \\
\hline Remnant & $27(39.7)$ & 7 (22.6) & $20(54.1)$ \\
\hline Missing data & 232 & 56 & 176 \\
\hline
\end{tabular}

Only the Brazilian study, in which $18 \%$ of patients were lost to follow-up, reported their reasons for abandoning the follow-up, the main one being absence of symptoms (11). In our study, the main reason was the absence of information concerning the need for follow-up. This may seem surprising for patients who have, in the main, been followed in the centre for years. The improvement patients observe in their symptoms during acromegaly therapy may lead them to believe that followup is no longer necessary, provided they continue their treatment. Indeed, most of these patients had not left the healthcare system, since $76 \%$ of them reported that they were receiving regular follow-up for their acromegaly from another doctor, usually a general practitioner. However, a small proportion of patients was clearly followed by a specialist, as evidenced by the seven patients who had been treated with additional surgery or radiotherapy. It is noteworthy that the tertiary centre had not been informed of these patients' progress once their care had been transferred to the community, reflecting the poor communication between primary care and hospitals.

Is it detrimental to patients to abandon specialist follow-up? We attempted to evaluate whether these patients' disease was well controlled by asking them and their doctor for information about their last IGF1 result and tumour progression. Regular assessment of these parameters is particularly important in these patients since, at their last follow-up visit, 30\% were uncontrolled, 33\% were receiving at least one treatment, $16 \%$ were controlled with treatment and 53\% had residual tumour at the last MRI.

Our analysis of the questionnaires suggests that they were not receiving optimal follow-up:

i) one-quarter of patients were not being monitored, and only one-third had seen an endocrinologist; ii) Twenty-eight percent of the patients traced were receiving treatment at their last follow-up visit, but only $15 \%$ were doing so when we traced them and

iii) the data collected from traced patients who did not attend the recall visit indicated inadequate follow-up: for example, only 61 of these 213 patients could provide an IGF1 result.

In chronic disease, interruption in follow-up denies patients the benefits of optimum treatment and highlights the weaknesses of an over-compartmentalised healthcare system with no real crossover between primary care and hospital care. Patients often lose motivation in the face of the demanding follow-up provided by specialist centres, which complies with guidelines but is far from their home and involves no collaboration with their local doctors. Various interventions to optimise the management of chronic disease have been evaluated $(23,24)$. Initiatives that should be developed to improve the long-term management of acromegalic patients include shared medical records, shared care based on the referring doctor's proximity to the patient, informing patients of the need for long-term follow-up, patient registries and recall systems. Finally, a likely reason (not evaluated in our study) for considering follow-up useless could also be the status of the clinician responsible for the last and previous follow-ups: patients seen by a temporary junior staff member could feel under-informed, leading to a lack of motivation to maintain follow-up in a reference centre. All these points suggest that there is still a lot of work to perform to obtain the optimal follow-up for patients with chronic and rare diseases.

Declaration of interest

The authors declare that there is no conflict of interest that could be perceived as prejudicing the impartiality of the research reported.

Funding

This study was supported by Novartis Pharma AG.

\begin{abstract}
Acknowledgements
The authors thank all participating centres: E Benamo (Avignon), $\mathrm{H}$ Bihan (Bobigny), F Bonnet (Rennes), F Borson-Chazot (Lyon), T Brue (Marseille), O Chabre (Grenoble), P Chanson (Le Kremlin Bicêtre), C Cortet-Rudelli (Lille), B Delemer (Reims), R Desailloud (Amiens), B Estour (St Etienne), L Foubert (Suresnes), A M Guedj (Nimes), N Gauthier-Jeandidier (Strasbourg), C Jublanc (Paris), V Kerlan (Brest), M Laloi-Michelin (Paris), R Maréchaud (Poitiers), I Raingeard (Montpellier), G Raverot (Lyon), Y Reznik (Caen), A Tabarin (Bordeaux), S Salenave (Le Kremlin Bicêtre), I Tauveron (ClermontFerrand), P Touraine (Paris), E Vidal (Limoges) and G Weryha (Nancy).
\end{abstract}




\section{References}

1 Melmed S. Medical progress: acromegaly. New England Journal of Medicine 2006355 2558-2573. (doi:10.1056/NEJMra062453)

2 Colao A, Ferone D, Marzullo P \& Lombardi G. Systemic complications of acromegaly: epidemiology, pathogenesis, and management. Endocrine Reviews 200425 102-152. (doi:10.1210/er.2002-0022)

3 Dekkers OM, Biermasz NR, Pereira AM, Romijn JA \& Vandenbroucke JP. Mortality in acromegaly: a metaanalysis. Journal of Clinical Endocrinology and Metabolism 200893 61-67. (doi:10.1210/jc.2007-1191)

4 Giustina A, Chanson P, Bronstein MD, Klibanski A, Lamberts S, Casanueva FF, Trainer P, Ghigo E, Ho K \& Melmed S. A consensus on criteria for cure of acromegaly. Journal of Clinical Endocrinology and Metabolism 201095 3141-3148. (doi:10.1210/jc.2009-2670)

5 Melmed S, Casanueva FF, Klibanski A, Bronstein MD, Chanson P, Lamberts SW, Strasburger CJ, Wass JA \& Giustina A. A consensus on the diagnosis and treatment of acromegaly complications. Pituitary 201316 294-302. (doi:10.1007/s11102-012-0420-x)

6 Melmed S, Colao A, Barkan A, Molitch M, Grossman AB, Kleinberg D, Clemmons D, Chanson P, Laws E, Schlechte J et al. Guidelines for acromegaly management: an update. Journal of Clinical Endocrinology and Metabolism 200994 1509-1517. (doi:10.1210/jc.2008-2421)

7 Arosio M, Reimondo G, Malchiodi E, Berchialla P, Borraccino A, De Marinis L, Pivonello R, Grottoli S, Losa M, Cannavo S et al. Predictors of morbidity and mortality in acromegaly: an Italian survey. European Journal of Endocrinology 2012167 189-198. (doi:10.1530/EJE-12-0084)

8 Holdaway IM, Bolland MJ \& Gamble GD. A meta-analysis of the effect of lowering serum levels of GH and IGF-I on mortality in acromegaly. European Journal of Endocrinology 2008159 89-95. (doi:10.1530/EJE-080267)

9 Ronchi CL, Rizzo E, Lania AG, Pivonello R, Grottoli S, Colao A, Ghigo E, Spada A, Arosio M \& Beck-Peccoz P. Preliminary data on biochemical remission of acromegaly after somatostatin analogs withdrawal. European Journal of Endocrinology $2008 \mathbf{1 5 8}$ 19-25. (doi:10.1530/EJE-07-0488)

10 Vilar L, Fleseriu M, Naves LA, Albuquerque JL, Gadelha PS, Dos Santos Faria M, Nascimento GC, Montenegro RM Jr \& Montenegro RM. Can we predict long-term remission after somatostatin analog withdrawal in patients with acromegaly? Results from a multicenter prospective trial. Endocrine 2014. In press.

11 Kasuki L, Marques NV, Nuez MJ, Leal VL, Chinen RN \& Gadelha MR. Acromegalic patients lost to follow-up: a pilot study. Pituitary 201316 245-250. (doi:10.1007/s11102-012-0412-x)

12 Chanson P, Bertherat J, Beckers A, Bihan H, Brue T, Caron P, Chabre O, Cogne M, Cortet-Rudelli C, Delemer B et al. French consensus on the management of acromegaly. Annales d'Endocrinologie 200970 92-106. (doi:10.1016/j.ando.2008.12.011)

13 Fieffe S, Morange I, Petrossians P, Chanson P, Rohmer V, Cortet C, Borson-Chazot F, Brue T \& Delemer B. Diabetes in acromegaly, prevalence, risk factors, and evolution: data from the French acromegaly registry. European Journal of Endocrinology 2011164 877-884. (doi:10.1530/EJE-10-1050)

14 Didoni G, Grottol S, Gasco V, Battistini M, Ferone D, Giusti M, Ragazzoni F, Ruffo P, Ghigo E \& Minuto F. Cost-of-illness study in acromegalic patients in Italy. Journal of Endocrinological Investigation 200427 1034-1039.

15 Lanoy E, Mary-Krause M, Tattevin P, Dray-Spira R, Duvivier C, Fischer P, Obadia Y, Lert F \& Costagliola D. Predictors identified for losses to follow-up among HIV-seropositive patients. Journal of Clinical Epidemiology 200659 829-835. (doi:10.1016/j.jclinepi.2005.11.024)

16 Corcostegui M, Haliou M, Durant J \& Dellamonica P. Tuberculeux perdus de vue en cours de traitement. Revue des Maladies Respiratoires 200623 127. (doi:10.1016/S0761-8425(06)72471-8)

17 Cordel N, Safa G, Balguerie X, De Preville P, Modeste A, Courville P, Boivin C, Pellerin A, Ziade J, Thiberville G et al. Inpatient and outpatient follow-up of grade I malignant melanoma. Annales de Dermatologie et de Vénéréologie 2000127 579-583.

18 Daly AF, Rixhon M, Adam C, Dempegioti A, Tichomirowa MA \& Beckers A. High prevalence of pituitary adenomas: a cross-sectional study in the province of Liege, Belgium. Journal of Clinical Endocrinology and Metabolism 200691 4769-4775. (doi:10.1210/jc.2006-1668)

19 Holdaway IM \& Rajasoorya C. Epidemiology of acromegaly. Pituitary 19992 29-41. (doi:10.1023/A:1009965803750)

20 Attanasio R, Montini M, Valota M, Cortesi L, Barbo R, Biroli F, Tonnarelli G, Albizzi M, Testa RM \& Pagani G. An audit of treatment outcome in acromegalic patients attending our center at Bergamo, Italy. Pituitary 2008 11 1-11. (doi:10.1007/s11102-007-0059-1)

21 Bex M, Abs R, T’Sjoen G, Mockel J, Velkeniers B, Muermans K \& Maiter D. AcroBel - the Belgian registry on acromegaly: a survey of the 'real-life' outcome in 418 acromegalic subjects. European Journal of Endocrinology 2007157 399-409. (doi:10.1530/EJE-07-0358)

22 Mestron A, Webb SM, Astorga R, Benito P, Catala M, Gaztambide S, Gomez JM, Halperin I, Lucas-Morante T, Moreno B et al. Epidemiology, clinical characteristics, outcome, morbidity and mortality in acromegaly based on the Spanish Acromegaly Registry (Registro Espanol de Acromegalia, REA). European Journal of Endocrinology 2004151 439-446. (doi:10.1530/eje.0.1510439)

23 Kripalani S, LeFevre F, Phillips CO, Williams MV, Basaviah P \& Baker DW. Deficits in communication and information transfer between hospital-based and primary care physicians: implications for patient safety and continuity of care. Journal of the American Medical Association 2007297 831-841. (doi:10.1001/jama.297.8.831)

24 Kripalani S, Yao X \& Haynes RB. Interventions to enhance medication adherence in chronic medical conditions: a systematic review. Archives of Internal Medicine 2007167 540-550. (doi:10.1001/archinte.167. 6.540)

Received 14 November 2013

Revised version received 19 February 2014

Accepted 3 March 14 